\title{
Sexually transmitted diseases on a tropical island
}

\author{
V. S. RAJAN \\ From Middle Road Hospital, Singapore
}

\section{Introduction}

Singapore is a bustling cosmopolitan island city, situated at the southern tip of Peninsula Malaysia. It is 602 square kilometres with a population density of 3784 persons per square kilometre. The population is made up of Chinese $(76 \%)$, Malays (15\%), Indians ( $7 \%$ ), and others $(2 \%)$. The distribution of the sexes in the population is equal except for Indians who still exhibit a migrant pattern with a sex ratio of 1.4 males to 1 female. The population is young with $60 \%$ between the ages of 15 and 59 years.

The growing and expanding economy has provided full employment for residents and it has attracted migrant workers from the region. Singapore today enjoys an annual per capita income of $\$ 5969$ (US\$2436), second only, in Asia, to Japan.

In recent years, there has been a tendency for women to be economically independent, seeking employment in the industrial and commercial sectors. The proportion of economically active women between the ages of 15 and 44 years has risen from $21 \%$ in 1957 to $42 \%$ in 1975 . Singapore is situated at the crossroads of international sea and air travel. In 1976, 1492218 tourists, businessmen, and officials visited the republic and stayed for about 3.3 days (Department of Statistics, 1977; Ministry of Health, 1977).

\section{Epidemiology}

Sexually transmitted diseases (STDs) have been notified only since 1 August 1977 under the Infectious Disease Ordinance. Hence, no national figures on the incidence of the different diseases are available except for those from public clinics. A survey showed that the true national incidence of syphilis and gonorrhoea was at least two and probably five times the reported incidence from public clinics (Morton,

Address for reprints: Dr V. S. Rajan, Middle Road Hospital, Singapore

Received for publication 18 November 1977
1971). Nevertheless, the epidemiological trends are clear.

In 1950 the incidence of infectious syphilis was 160 per 100000 population and gonorrhoea 325 per 100000 population. In the early 1960 s, these figures dropped to between 7 and 9 for syphilis and 125 for gonorrhoea; since then there has been a steady increase. In 1970, the incidence of gonorrhoea and infectious syphilis was 136 and 14 respectively per 100000 population. In 1975 , the rates were 21.4 for syphilis and 149 for gonorrhoea per 100000 population. It is of interest to note that the number of cases of infectious syphilis dropped from 428 in 1975 to 201 in 1976 . A further $40 \%$ decrease has been recorded for the first half of 1977 . The gonorrhoea rates for 1976 have gone up but the redeeming feature has been the marked improvement in the identification rates in women. This has remained so for the first half of 1977 and, surprisingly, the number of infections of gonorrhoea in women has outstripped that in men by $3: 1$. A $20 \%$ drop in infections in men has been recorded for the first half of 1977. In 1976, 1627 cases of chancroid, 88 cases of lymphogranuloma venereum, 255 cases of genital herpes, 461 cases of non-specific urethritis, and 559 cases of venereal warts were reported. Singapore is one of the few countries that has reported high figures for chancroid and lymphogranuloma venereum.

The age groups affected by STDs are mainly between 20 and 24 years $(30 \%)$, and between 25 and 29 years $(21 \%)$. In men, $18.5 \%$ are between the ages of 15 and 19 years but only $5.6 \%$ of women are in this age group. Thus promiscuity in the female appears to begin later than is witnessed in the West. Few cases of acquired STDs are seen in either boys or girls under the age of 18 years. The index case in $60 \%$ of patients is a female prostitute; $13.5 \%$ of patients are infected overseas. Homosexuality is not a problem here (Middle Road Hospital, 1950-76). A study of prostitutes showed that $46 \%$ have syphilis, $8 \cdot 5 \%$ gonorrhoea, $14.5 \%$ asymptomatic chancroid, and $64 \%$ possibly have asymptomatic or old chlamydial infections. This same study showed that only $5 \%$ were free of any STD (Khoo et al., 1977). 


\section{Control aspects}

The epidemiological data show that health education and control are very important if the incidence of infection is to be reduced in the biggest group at risk. As there is little infection in boys who are under the age of 18 years and in girls under 20 years, health education programmes are aimed at reaching the general public, children in their final years at school, and boys doing National Service. An islandwide national health campaign against six infectious diseases including STDs was launched in 1976, followed by a booster campaign on STDs alone in September 1977. Pre- and post-campaign assessment showed a statistically significant increase in knowledge of STDs in secondary schoolchildren and in uniformed personnel in the armed forces. The campaign's impact on change of attitudes is being assessed.

Prostitutes (male and female) are the largest reservoir of infection. Although their existence has no legal sanction, their role in the spread of STDs and the need to control disease in this group of people is recognised. Hence a Medical Scheme incorporating the assistance and functions of the police department, computer services department, laboratory, clinical services, and general practitioners participating in the scheme, was launched in August 1976. The philosophy of the scheme has been one of persuasion and the use of subtle legal pressures to ensure its success. In the brothels today, $85 \%$ of the prostitutes in the scheme are readily accessible for periodic checks and treatment when found to be infected. The dramatic reduction in infectious syphilis during the past two years, the $20 \%$ drop in the rate of gonorrhoea in men during the first half of 1977 , and the $3: 1$ female to male ratio for the incidence of gonorrhoea can be attributed to the success of this scheme.

We have adopted the following policy on epidemiological treatment. All contacts are investigated but are not routinely treated. However, if epidemiological evidence strongly suggests an infection, the contact is treated after relevant tests have been performed. In the Medical Scheme, only those found to be infected are treated and no routine epidemiological treatment is offered.

Doctors and laboratories are now obliged to notify cases of gonorrhoea, non-specific urethritis, infectious and non-infectious syphilis, chancroid, and also cases of genital discharge and ulcers not specifically diagnosed but considered to be of venereal origin. The notification is on a nonnominal basis but the patient's age and sex has to be given. Practitioners are encouraged to provide information on the patient's sexual contacts to the
Sexually Transmitted Diseases Epidemiological Control Unit if their patient has no objection. In a country where patients frequently change their doctors, over-reporting is possible.

Singapore was one of the first countries in the world to report $\beta$-lactamase producing strains of gonococci. During the past 15 months only 20 strains have been isolated out of more than 7000 tested. The Central Neisseria Laboratory routinely tests all isolates for penicillin resistance. When detected the patient and all sex contacts are immediately traced and treated. We favour the use of kanamycin for treating $\beta$-lactamase strains, and we have had no failures with a single $2 \mathrm{~g}$ injection.

\section{Treatment facilities}

Patients with STDs have the choice either of seeking treatment from a general practitioner or attending a public clinic run by the hospital division of the Ministry of Health. The speciality is combined with dermatology and a teaching hospital is the national centre for the combined speciality and epidemiological control. Treatment of STDs is free. Treatment and laboratory facilities are of good standard. The national laboratory is well equipped with facilities to perform 800 VDRL (Venereal Disease Research Laboratory) tests, 50 FTA/ABS (fluorescent treponemal antibody absorption) tests, and 1000 gonococcal cultures a day. Facilities to isolate mycoplasma and Chlamydia are available, and cultures for Haemophilus ducreyi are also routinely performed. The standard of clinical practice in the private sector leaves something to be desired. A recent survey showed that gonorrhoea is mostly diagnosed on clinical grounds, although serological tests for syphilis are more frequently requested in patients with genital ulcers. About six private laboratories have facilities to perform serological tests and gonococcal cultures.

For the treatment of syphilis, the long acting benzathine penicillin is recommended. For gonorrhoea, we favour an 'instant treatment' schedule and either 3 megaunits of injection procaine penicillin or $2 \mathrm{~g}$ of ampicillin with probenecid is the standard treatment. Fifty-two per cent of local strains of gonococci are less susceptible to penicillin but with this dosage the treatment failure rate is less than $4 \%$. As second line drugs-and for $\beta$-lactamase producing strains-injection kanamycin $2 \mathrm{~g}$, injection kanandomycin $1.2 \mathrm{~g}$, or injection spectinomycin $2 \mathrm{~g}$ is recommended. The same dosage is used for men and women. In our experience against local strains, all bacteriostatic antibiotics-such as the tetracyclines used in instant treatment regimens - have given poor results and are not recommended. 
For chancroid, 7 to 10 days of tetracycline $1 \mathrm{~g}$ daily or streptomycin $1 \mathrm{~g}$ daily is routinely recommended. Better results are obtained with streptomycin. Clinical trials indicate that co-trimoxazole is a promising alternative. For lymphogranuloma venereum and non-specific urethritis, tetracyclines for two or three weeks are recommended.

In all patients with infectious syphilis and gonorrhoea, attempts are made to trace sex contacts. On the average we have a $30 \%$ success rate.

\section{Teaching}

There is no full-time department of dermatovenereology in the university. Government specialists are employed, part-time, to teach this subject. Undergraduates receive 96 hours of teaching in the combined speciality during their fourth and final years of training. The whole spectrum of STDs is taught and students are encouraged to take specimens for darkground examination and smears, and to examine the slides. Due emphasis is given to epidemiology and control.

In the final year the student is obliged to sit for an assessment test in the speciality. Questions on STDs are included in the final year multiple choice paper in medicine.
Candidates doing postgraduate courses in medicine, obstetrics, and gynaecology attend a two-hour session in venereology. For general practitioners occasional courses are held in conjunction with the College of General Practitioners. Standard recommendations and treatment guidelines are published periodically in the Epidemiological News Bulletin published by the Ministry of Health and distributed free of charge to all registered medical practitioners in the republic.

STD is not a neglected discipline. The government has been concerned at the way it has spread and has given support to control it. It has been the national policy to share our advanced facilities and expertise with neighbouring countries so that there is international participation and co-operation in curbing this modern plague.

\section{References}

Department of Statistics (1977). Monthly Digest of Statistics, volume 16, No. 8. Department of Statistics: Singapore.

Khoo, R., Sng, E. H., and Goh, A. J. (1977). Incidence of sexually transmitted diseases in prostitutes in Singapore. Asian Journal of Infectious Diseases, 1, 77.

Middle Road Hospital (1950-76). Annual Reports. Middle Road Hospital: Singapore.

Ministry of Health (1977). Population and Trends. MOH: Singapore. Morton, R. S. (1971). Assignment Report-VD Control, Singapore, 1 November 1969 to 30 April 1970. WHO: Geneva. 